\title{
Uma Perspetiva sobre o Relatório da OCDE "Health at a Glance 2017'"
}

\section{A Perspective on the OECD Report "Health at a Glance 2017"}

Luís CAMPOS $\square^{1,2,3}$

Acta Med Port 2018 Jan;31(1):9-11 - https://doi.org/10.20344/amp.10111

Palavras-chave: Assunção de Riscos; Gastos em Saúde; Indicadores Básicos de Saúde; Qualidade, Acesso e Avaliação de Cuidados de Saúde; Organização de Cooperação e Desenvolvimento Económico; Portugal; Recursos em Saúde

Keywords: Health Care Quality, Access, and Evaluation; Health Expenditures; Health Resources; Health Status Indicators; Organization for Economic Co-Operation and Development; Portugal; Risk-Taking

\section{INTRODUÇÃO}

É sempre com imensa curiosidade que aguardamos a publicação deste relatório anual da Organização de Cooperação e Desenvolvimento Económico (OCDE) porque é a fonte mais credível e completa sobre a evolução comparada dos indicadores de Saúde de um vasto painel de países integrados na organização. Existem limitações sempre inerentes a uma publicação com esta envergadura, nomeadamente em relação ao paralelismo dos anos reportados, à comparabilidade dos universos a que os indicadores dizem respeito e à falta de informação sobre alguns indicadores em relação a alguns países, mas são limitações inevitáveis. ${ }^{1,2}$

Para prevenir uma dispersão da análise vou agregar os indicadores dos 11 capítulos que constam no relatório em seis categorias: comportamentos de risco, despesas em Saúde, recursos, acesso, estado de Saúde, e qualidade. Os últimos dados referem-se geralmente ao ano de 2015 e, quando se referir a população adulta, esta inclui as pessoas com 15 ou mais anos.

Naturalmente que não vou fazer uma revisão exaustiva de todo o relatório pelo que os destaques são sobretudo produto de uma visão pessoal sobre a relevância da informação contida no relatório e vão incidir mais sobre os números referentes a Portugal.

De uma forma global, existem alguns fenómenos transversais aos países da OCDE, dos quais destaco o aumento da esperança de vida, que se situa na média dos 80,6 anos (mais 10 anos do que em 1970), vivendo as mulheres mais cinco anos que os homens, o aumento das doenças crónicas e o peso das doenças vasculares, que representam uma em cada três mortes, no entanto com uma tendência para a diminuição da mortalidade por esta causa.

Portugal apresenta um bom desempenho em função do dinheiro que gasta em Saúde, mas tem alguns problemas, particularmente nas áreas dos comportamentos de risco, do acesso, da qualidade dos cuidados e da Saúde e cuidados aos nossos idosos, que carecem de atenção e de serem corrigidos. A Tabela 1 ajuda a identificar os indi- cadores onde Portugal se coloca nos extremos, entre 173 indicadores analisados. No fim, é para nos ajudar a identificar estes desvios que estes relatórios servem.

\section{Comportamentos de Risco}

A análise dos comportamentos de risco é muito importante, não só porque representam cerca de $40 \%$ dos determinantes da Saúde como servem para monitorizar a eficácia das políticas públicas. Nesta área há boas e más notícias. $^{3}$

Relativamente aos hábitos tabágicos assistiu-se a uma diminuição de $20,6 \%$ da população com 15 ou mais anos, em 1999, para 16,8\%, em 2014, embora esta diminuição tenha acontecido à custa dos homens, porque nas mulheres houve um ligeiro crescimento. Este valor situa-nos um pouco abaixo da média da OCDE $(18,4 \%)$, no entanto esta redução tem acontecido em todos os países e Portugal está entre os três países onde foi menos conseguida.

O consumo de álcool desceu nos últimos dez anos, tendo passado de 13,5 litros por pessoa, em 2004, para 9,9 litros, em 2014, mantendo-se mesmo assim acima da média dos países da OCDE $(9,0 \mathrm{l})$.

No que se refere à actividade física percebe-se que os portugueses não são muito aficionados: apenas $57,1 \%$ da população adulta tem uma actividade física moderada semanal, menos que nós só a Itália e de Espanha, sendo o valor médio dos países da OCDE de 66,5\%.

Relativamente à dieta, a análise dos indicadores mostra que $70,9 \%$ da população adulta come fruta diariamente, muito acima da média dos países da OCDE $(56,8 \%)$, mas só $55,25 \%$ come diariamente vegetais, abaixo da média da OCDE $(59,8 \%)$, valor que ainda baixa mais nas nossas crianças (23\%).

A inatividade física e os erros alimentares contribuem diretamente para que a percentagem da população adulta com sobrecarga ponderal ou obesidade auto referidas seja de $53 \%$.

\footnotetext{
1. Presidente. Sociedade Portuguesa de Medicina Interna. Lisboa. Portugal.

2. Presidente. Comissão de Qualidade e Assuntos Profissionais. European Federation of Internal Medicine. Bruxelas. Bélgica.

3. Diretor. Serviço de Medicina. Hospital São Francisco Xavier. Centro Hospitalar Lisboa Oriental. Lisboa. Portugal.

$\triangle$ Autor correspondente: Luís Campos. luisbarretocampos@gmail.com

Recebido: 19 de dezembro de 2017 - Aceite: 20 de dezembro de 2017| Copyright @ Ordem dos Médicos 2018
} 
Tabela 1 - OECD 2017 top/bottom three*

\begin{tabular}{|c|c|c|}
\hline & $\begin{array}{l}\text { Indicadores em que Portugal está colocado } \\
\text { entre os três países pior colocados }\end{array}$ & $\begin{array}{c}\text { Indicadores em que Portugal está colocado entre } \\
\text { os três países melhor colocados }\end{array}$ \\
\hline \multirow{2}{*}{$\begin{array}{l}\text { Comportamentos } \\
\text { de Risco }\end{array}$} & Actividade física semanal moderada entre adultos & \multirow{2}{*}{$\begin{array}{l}\text { Consumo excessivo de álcool (pelo menos uma vez } \\
\text { por mês) por género }\end{array}$} \\
\hline & Ingesta diária de vegetais entre jovens de 15 anos & \\
\hline \multirow[t]{2}{*}{ Despesas em Saúde } & \multirow{2}{*}{$\begin{array}{l}\text { Taxa média anual de crescimento da despesa } \\
\text { em saúde per capita entre } 2009 \text { e } 2016\end{array}$} & Despesas de saúde em cuidados ambulatórios \\
\hline & & $\begin{array}{l}\text { Despesas em internamento no contexto da despesa } \\
\text { hospitalar }\end{array}$ \\
\hline \multirow[t]{2}{*}{ Recursos } & & Médicos por mil habitantes \\
\hline & & $\begin{array}{l}\text { Rácio generalistas/especialistas no conjunto de todos } \\
\text { os médicos }\end{array}$ \\
\hline Acesso & $\begin{array}{l}\text { Despesa out-of-pocket com serviços de saúde e } \\
\text { produtos }\end{array}$ & Densidade de médicos nas áreas rurais e urbanas \\
\hline \multirow{5}{*}{$\begin{array}{l}\text { Qualidade dos } \\
\text { Cuidados e } \\
\text { Resultados de Saúde }\end{array}$} & $\begin{array}{l}\text { Doentes com } 65 \text { e mais anos que têm prescrições } \\
\text { para benzodiazepinas por mais de um ano }\end{array}$ & $\begin{array}{l}\text { Percentagem de médicos que envolvem os doentes } \\
\text { em decisões sobre cuidados e tratamento }\end{array}$ \\
\hline & \multirow{2}{*}{$\begin{array}{l}\text { Percentagem de doentes com fractura do colo } \\
\text { do fémur operados nos primeiros dois dias pós } \\
\text { admissão no hospital }\end{array}$} & $\begin{array}{l}\text { Doentes com diabetes com medicação anti- } \\
\text { hipertensiva recomendada prescrita no ano anterior }\end{array}$ \\
\hline & & Admissão hospitalar por asma e DPOC em adultos \\
\hline & \multirow[t]{2}{*}{ Consumo de antidepressivos por mil habitantes } & $\begin{array}{l}\text { Embolia pulmonar pós-operatória (PE) ou trombose } \\
\text { venosa profunda (TVP) em cirurgias à anca e joelho }\end{array}$ \\
\hline & & $\begin{array}{l}\text { Mamografia em mulheres de } 50 \text { a } 69 \text { anos nos últimos } \\
2 \text { anos }\end{array}$ \\
\hline \multirow[t]{2}{*}{ Estado de Saúde } & \multicolumn{2}{|l|}{$\begin{array}{l}\text { Incidência de leucemia em crianças de } 0 \text { a } 14 \\
\text { anos }\end{array}$} \\
\hline & \multicolumn{2}{|l|}{ Prevalência de Depressão crónica } \\
\hline
\end{tabular}

*Elaboração própria a partir do relatório "OECD Health at a Glance 2017"

\section{Despesas em Saúde}

Começando pela despesa em Saúde per capita, esta foi, em 2016, de 2734 dólares americanos (USD), mais 1088 dólares que há 15 anos, mas inferior à média da OCDE (USD 4003). No entanto, no conjunto dos 35 países, em quatro deles essa despesa caiu entre 2009 e 2016 e Portugal é o segundo país onde essa despesa mais caiu $(-1,3 \%)$, só ultrapassado pela Grécia $(-5,0 \%)$. Este é um bom indicador para constatar a grande diversidade dos países da OCDE: os Estados Unidos da América (EUA), o país que gasta mais em Saúde per capita (USD 9892), gasta 37 vezes mais do que o país que gasta menos (Índia: USD 269). Este é também um bom indicador para analisar a eficiência dos sistemas de Saúde, cruzando a despesa em Saúde per capita com a esperança de vida em cada país: nessa análise verifica-se que Portugal tem um claro desvio positivo enquanto os EUA é o país que mais se destaca abaixo da curva.

A despesa em Saúde em Portugal representa 9,9\% do produto interno bruto (PIB), muito próximo da média da OCDE $(9,0 \%)$, no entanto $33 \%$ da despesa é privada, percentagem bem acima da média da OCDE (26\%), valor que tem crescido nos últimos seis anos.

Em relação à despesa em fármacos, onde tínhamos um grande desequilíbrio, reduzimos de $20,2 \%$ das despesas em Saúde, em 2009, para 15,5\% em 2015, tendo Portugal sido o segundo país em que este despesa mais desceu nesse período, logo depois da Grécia, no entanto é ainda superior à média dos países da OCDE $(12,2 \%)$.

\section{Recursos em Saúde}

No que respeita aos recursos humanos verificamos que Portugal é o terceiro país da OCDE com mais médicos por mil habitantes $(4,6)$, sendo a média da OCDE de 3,4 médicos. Outro dado em que nos destacamos, creio que positivamente, é que somos o segundo país com maior percentagem de médicos generalistas $(51 \%)$, sendo a média da OCDE de $30 \%$.

Em relação aos enfermeiros, temos 6,3 enfermeiros por mil habitantes, muito abaixo da média da $\operatorname{OCDE}(9,0)$, com um ratio enfermeiros/médicos $(1,4)$ também muito abaixo da média da OCDE $(2,8)$.

Um dado preocupante é o número de camas hospitalares por mil habitantes $(3,4)$, muito abaixo da média da OCDE $(4,7)$, número que desceu nos últimos 15 anos. No entanto somos o segundo país da OCDE com menor taxa de ocupação (64\%) quando a média da OCDE é de $75,7 \%$, o que representa um desperdício e a necessidade de mudar alguma coisa na gestão comum de camas e numa organização demasiado fragmentada dos hospitais.

\section{Acesso a Cuidados de Saúde}

No que se refere ao acesso a cuidados de Saúde, destaco que $26 \%$ da população já tem um seguro privado de saúde, estando Portugal entre os seis países em que mais cresceu esta percentagem.

Uma percentagem significativa da população não faz medicação por razões de custos dos medicamentos $(10,1 \%)$. Em contrapartida os portugueses são quem dedica a maior percentagem das despesas domésticas a 
cuidados ambulatórios, incluindo consultas (56\%).

Temos valores superiores à média dos países da OCDE no que se refere à densidade de médicos por mil habitantes nas zonas urbanas $(5,4)$ em relação às zonas rurais $(2,2)$, no entanto somos dos países em que esta diferença é maior (2,2 médicos).

Portugal aparece no quadro evolutivo dos tempos de espera para cirurgia, entre 2006 e 2015, onde podemos constatar que, depois de ter diminuído significativamente estes tempos entre 2006 e 2011, se assiste a uma inversão desta descida a partir desse ano.

\section{Qualidade dos Cuidados}

No que se refere à qualidade dos cuidados destaco, pela negativa, que somos o segundo país de um grupo de 16 países da OCDE que tem a maior taxa de prescrição de benzodiazepinas por mil idosos com duração superior a um ano (54), mais do dobro da média deste grupo de países (25). Outro indicador preocupante, porque tem relação direta com a mortalidade, é o de que apenas $46,5 \%$ dos doentes admitidos por fratura do colo do fémur ser operado nos primeiros dois dias. Nos países da OCDE a média é de $80,9 \%$. Mais grave ainda é o facto de termos sido o único país em que este tempo aumentou nos últimos dez anos.

Pela positiva, destaco o facto de sermos o terceiro país que teve, em 2015, menos internamentos por asma ou DPOC (74 / 100000 habitantes), o que representa menos de um terço da média da OCDE, e o quinto que teve menos internamentos por complicações da diabetes (66 / 100000 habitantes), o que quer dizer que estamos a fazer um bom trabalho nos cuidados ambulatórios destas doenças. Outro indicador impressivo é a taxa de mulheres que fazem rastreio de cancro da mama por mamografia entre os 50 e 69 anos: $80,9 \%$. Apenas somos ultrapassados pela Suécia, sendo a média da OCDE de 60,8\%. Notável foi também a evolução da cirurgia ambulatória, demonstrada na evolução de menos de $10 \%$ das cirurgias de catarata realizadas em ambulatório em 2000 para 96,7\% em 2015,

\section{REFERÊNCIAS}

1. OECD. Health at a Glance 2017: OECD Indicators. Paris: OECD Publishing; 2017. [consultado 2017 dez 9]. Disponível em: http://www.oecd-ilibrary.org/social-issues-migration-health/health-at-a-glance-2017_ health_glance-2017-en.

2. OECD. OECD Health Statistics 2017. Paris: OECD Publishing; 2017. superior à média da $\operatorname{OCDE}(86,8 \%)$. Finalmente destaco a taxa de cesarianas $(32,3 \%)$ que continua a ser superior à média da OCDE $(27,9 \%)$, apesar de termos melhorado desde há cinco anos a esta parte, altura em que tínhamos 35,8 cesarianas por 100 partos.

\section{Estado de Saúde}

Portugal tem uma esperança média de vida de 81,1 anos, um pouco superior à média dos países da OCDE $(80,6)$, sendo a esperança de vida das mulheres superior em 6,2 anos à dos homens. Curiosamente esta tendência de crescimento foi interrompida no nosso país, tendo diminuído 0,1 anos, de 2014 para 2015.

A população idosa representa $20 \%$ da população, percentagem superior à média da $\mathrm{OCDE}(17 \%)$, mas as projeções demográficas apontam para que Portugal tenha, em 2050 , uma percentagem de idosos superior a $35 \%$, tornando-se o terceiro país da OCDE com mais idosos, depois do Japão e Espanha.

Para além de sermos uma população muito idosa, os nossos idosos são mais doentes e incapacitados: o número de anos de vida saudável depois dos 65 é de 6,2 anos, inferior à média da $\operatorname{OCDE}(9,4)$ e muito inferior à Suécia, onde os idosos podem contar ainda com 16,3 anos de vida saudável, e a percentagem da população idosa com algum tipo de incapacidade é de $45,5 \%$, muito superior aos $32,7 \%$ de média nos países da OCDE.

Em contraste com a dimensão deste problema no nosso país, somos o país onde a apenas $2,1 \%$ da população idosa recebe cuidados de longo termo, sendo que essa percentagem é de $13,0 \%$ nos países da OCDE.

$\mathrm{Na}$ análise das principais causas de morte verificamos que as doenças vasculares seguidas do cancro continuam à cabeça, mas na doença cerebrovascular temos uma mortalidade superior à média da OCDE (85 / 65 por 100 mil habitantes). É notável a redução de $55 \%$ na mortalidade por doença cardiovascular e de $74 \%$ por doença cerebrovascular nos últimos 25 anos.

[consultado 2017 dez 9]. Disponível em: http://www.oecd.org/els/health-systems/health-data.htm.

3. McGinnis JM, Williams-Russo P, Knickman J. The case for more active policy attention to health promotion. Health Aff. 2002;21:78-93. 